\title{
III - A ocorréncia das células anexas dos estomatos na família Rubiaceae
}

\author{
WALTER RADAMES ACCORSI \\ Prof. de Botanica Geral e Descritiva \\ da Escola Superior de Agricultura "Luiz de Queiroz". \\ da Universidade de \$šo Paulo
}

INDICE

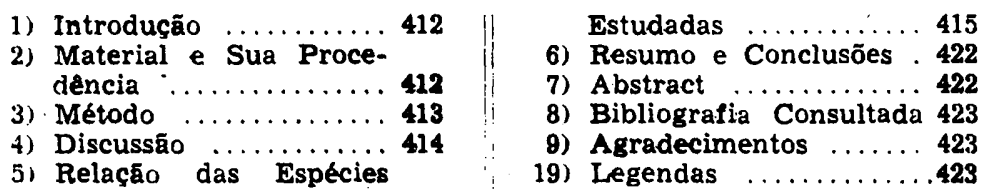




\section{I -INTRODUÇÃO}

No presente trabalho, o terceiro que publico sóbre 0 assunto, concluo os estudos e as observações que venho fazendo em tôrno da ocorrência das células anexas dos estômatos, entre as Rubiáceae, com o propósito de averiguar o valor sistemático delas, como caráter de familia.

De acórdo com os trabalhos que publiquei $(1,2)$, as minhas primeiras investigações sôbre as células anexas dos estômatos das Rubiaceae foram feitas na epiderme inferior das follhas de Coffea arabica L.. Posteriormente, analisei, com o mesmo intúito, as Rubiaceae cultivadas no Parque da "Luiz de Queiroz", num total de 20 espécies, distribuidas em 9 gêneros. Em tôdas, pude verificar a presença das duas células anexas, adjacentes às células dos estômatos. A vista dos resultados obtidos, julguei interessante e oportuno estender as observações ao maior núinero de gêneros e espécies, pois a ocorrência das células anexas poderia constituir uma caracteristica das Rubiaceae. Para àtingir ésse objetivo duas hipóteses deveriam ser preenchidas :

1 - Que da.ordem Rubiales a familia Rubiaceae Pâsse a única a exibir estómatos circundados de duas células anexas.

2 - Que a presença das duas células anexas fásse constante nas espécies e gêneros da familia, constituindo uma caracteristica diferencial, no caso de sua inconstância.

A primeira hipótese foi inteiramente demonstrada com os estudos que realizei sôbre as familias Rubiaceae, Caprifoliaceae, Valerianaceae e Dipsacaceae, pertencentes à ordem Rubiales (5). As conclusões a que cheguei estão publicadas na revista "O Solo" (1). Quanto à segunda hipótese, resolví estudar, preliminarmente, as espécies e variedades do importante gênero Coffea, servindo-me, para tanto, do excelente material existente nas coleções da Secção de Café, do Instituto Agronómico de Campinas (2).

Nesta terceira publicação, apresento as conclusões gerais relativas a 553 espécies de Rubiaceae, distribuidas por 107 gêneros, provenientes de várias regiōes.

\section{II - MATERIAL E SUA. PROCEDENCIA}

Elaborado o plano definitivo para o estudo da organização dos estômatos na familia Rubiaceae, o primeiro passo a dar, 
nesse sentido, consistiu na aquisição de apreciável quantidade de material, abrangendo o máximo de gêneros e espéces. Diante da extensão do campo a investigar e considerando a necessidade de chegar-se a um resultado no mais curto espaço de tempo, só me restava uma alternativa: solicitar amostras de fôlhas de Rubiaceas dos herbários, ou de plantas cultivadas nas culeções e viveiros, dos Institutos e Estaçð̃es Experimentais. Enquanto aguardava a chegada do material pedido, pude reunir, de diversas procedências, cêrca de 60 espécies.

As espécies Galium aparine L. e Rubia tinctoria Salisb. foram colhidas, por mim, na Facultad de Agronomia y Veterinária de Buenos Aires, em junho de 1945. As espécies Cinchona Ledgeriana Moens., Cinchona Calysaia Wedd. var. Josephiana e Cinchona succirubra Pav. são provenientes das coleçסes de quineiras do Instituto Agronômico de Campinas.

Todavia, a quase totalidade das espécies estudadas - 546 amostras foliares herborizadas, foi-me enviada pelo eminente botânịco Dr. João Geraldo Kuhlmann, digníssimo diretor do Jardim Botânico do Rio de Janeiro. A valiosissima contribuição do Dr. J. G. Kuhlmann foi decisiva para a conclusão dos estudos levados a efeito nesse campo, pois dificilmente poderia ter à mão, de uma só vez, o acêrvo de espécies analisadas.

\section{III - METODO}

Feita a exclusão das numerosas espécies em duplicata e daquelas já estudadas, procedeu-se à extração das epidermes, trabalho êsse que esteve a cargo da Dra. Odete $Z$. de Toledo, então Biologista da Cadeira de Botânica da "Luiz de Queiroz" O método de extração adotado foi o mesmo que empreguei nos trabalhos anteriores. Devido à natureza peculiar das fôlhas de muitas espécies, como presença de compacto revestimento de pêlos, forte aderência da epiderme ao mesofilo, etc., etc., houve necessidade de se modificar o método geral. Assim, muitas epidermes somente foram conseguidas por meio de cortes paralelos à superfície foliar. Em outras, foi preciso o emprêgo do escalpelo e da gilete para a remoção do indumento piloso. Mesmo assim e apesar de tôdas as tentativas feitas, as epidermes das seguintes espécies não puderam ser destacadas:

1 - Declieuxia ericoides Standl.

2 - Declieuxia saturejoides M. Arg.

3 - Guettarda platypoda DC.

4 - Retiniphylum secundiflorum H.B.K.

5 - Sabicea amazonica Wernh. 


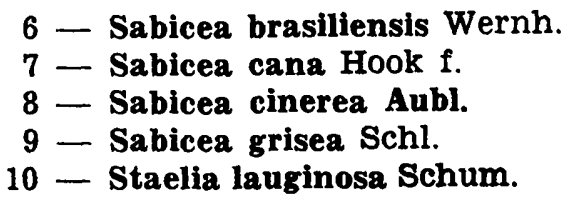

Esse fato, entretanto, em nada veio alterar as observações em andamento, uma vez que havia mais de uma espécie dos gêneras acima mencionados, cuja epiderme se destacou fàcilmente.

Via de regra, a extração da epiderme fez-se sem dificuldades, após prévio tratamento das fólhas com água quente. A montagem das láminas foi feita em glicerina. Para a obtenção dos desenhos, utilizei-me do microscópio Universal "Me F", empregando o seguinte jógo ótico : objetiva $100 \mathrm{X}$ n. p. e ocular 5X.

\section{IV - DISCUSSAO}

Do estudo pormenorizado que fiz das epidermes foliares de 553 espécies de Rubiaceae, pertencentes a 107 gêneros, verifiquei que tódas exibiam, sem exceçáo, em seus estómatos as duas células anexas, de tamanho, forma, contôrno, etc., etc., distintos, sendo, na maioria dos individuos estudados, uma celula maior que a outra.

Devo salientar que o contorno das células anexas, no mesmo estômato, é variável, podendo ser, tanto de uma como de outra, arqueado, ondulado, crenado, poligonal, misto (ondulado-arqueado, arqueado-poligonal, etc).

A disposiçăo e a inserçăo das células anexas no estomato enquadram-se dentro dos tipos estudados, isto é, implantam-se, qase sempre, na extremidade da fenda estomatar pelo prolongamento comum da membrana, à semelhança de duas alças. como se depreende do exame dos desenhos.

No decurso dos exames microscópicos, muitas particularidades da epiderme e dos estómatos puderam ser registradas, tais como : presença de majs um par de células anexas, à volta do primeiro e com idêntica disposiçăo; aspectos diversos da configuração estomatar, no mesmo trecho de epiderme, etc., etc., afora numerosos pormenores citológicos e estruturais. A relação dessas minúcias será objeto de um trabalho a ser publicado.

Após as considerações relativas à organização dos estomatos das Rubiaceae constantes déste e dos trabalhos publicados $(1,2)$, perfazendo um total de 601 espécles, distribuidas em 107 gêneros, cheguei à conclusão de que tôdas, invariàvelmente, os- 
tentam nos seus estômatos as duas células anexas. Todavia, para o estudo completo da familia faltam, ainda, numerosos gêneros e espécies, como se deduz do seguinte trecho de Loefgren (3) : "A familia Rubiaceae possui 343 gêneros, com distribuiçăo uniforme por tóda a zona tropical, com mais de 4.500 espécies, sendo muitas incertas". Dos gêneros brasileiros, conforme divirāo seguida por Loefgren (3), năo puderam ser estudados, por falta de material, os seguintes : Cassupa, Chalepophyllum, Condaminea, Exostema, Joosia, Leptoscella, Limnosipanea, Ouroparia, Pallasia, Phitopis, Salzamannia, Schenckia, Sherardia e Stilpnophyllum.

Como se vé, a famflia Rubiaceae é grande e com vasta distribuiçáo geográfica. Seu estudo integral, envolvendo a totalidare dos gêneros, torna-se complexo e difícil. Entretanto, pelo fato de năo ter encontrado uma discordancia s!quer nas numerosas espécies dos 107 gêneros estudados, é bem provável que as rspécies ainda por examinar revelem as duas células anexas nos estómatos, com as características assinaladas.

Corroborando o meu ponto de vista, cito a nova e interesrantissima espécie Dialypetalanthus fuscescens Kuhlmann (4) (espécle e gênero novos, descritos por J .G. KUHLMANN), a qual, a.pesar das peculiares características especificas, possui, também, duas células anexas nos seus estómat's (fị. 14). J. KUHLMANN, ao descrever a planta (4), assim se exprime: "Das plantas que têm sido colhidas ùltimamente na Amazônia, o gênero acima descrito constitui evidentemente, uma dns formas mais raras e representa, devdo à corola de pétalos livres e o número indefinido de estames, um caso raríssimo e talvez único dentro da familia e em tôdas as gamopetalas ínfero-ovariadas (?). O seu parentesco com as Rubiaceas é inatacável, vindo porém a constituir uma tribo distinta próxima das Cinchoneac."

Diante de tudo quanto foi exposto, analisado, observado, posso considerar as células anexas dos estomatos das Rubiaceae como um caráter anatómico de família.

\section{V - RELAÇAO DAS ESPECIES ESTUDADAS}

1 - Alibertia acuminata Sandw.

2 - Alibertia amplexicaulis S. Moore

3 - Alibertia bertierifolia Schum.

4-Alibertia concolor (Cham.) K. Schum.

5 - Alibetia dolichophylla Standl.

f: - Alibertia Duckei Standl.

7 - Alibertia edults A. Rich.
8 - Alibertia elliptica Schum.

9 - Alibe:tia hadrantha Standl.

10 - Alibertia hispida Ducke

11 - Alibertia humilis Schum.

12 - Alibertia iquitensis Ducke

13 - Alibertia latifolia Schum.

14 - Alibertia myrcifolia K. Schum.

15 - Alibertia obidensis Eub. 
16 - Alibertia triflora Schum.

17 - Alseis floribunda Schott.

18 - Alseis longifolia Ducke

19 - Amajoua corymbosa H. B. K.

20 - Amajoua guianensis Aubl.

21 - Amajoua laureaster Mart.

22 - Anisomeris bella Standl.

23 - Anisomeris brasiliana Standl.

24 - Anisomeris grandifolia Hub.

25 - Anisomeris modesta Standl.

26 - Anisomeris obtusa Sohum.

27 - Anisomeris occidentalis Standl.

28 - Anisomeris paniculata Standl.

29 - Anisomeris Preslii K. Schum.

30 - Anisomeris pubescens Schum.

31 - Anisomeris ribesioides

32 - Appunia triphylla Ducke

33 - Augusta lanceolata Pohl.

34 - Basanacantha altiscandens Ducke

35 - Basanacantha hispida Ducke

36 - Basanacantha spinosa Schum.

37 - Bathysa australis (St. Hill.) Hook

38 - Bathysa cuspidata Hook $f$

39 - Bathysa gymnocarpa Schum.

40 - Bathysa Mendonçai Schum.

41 - Bathysa Nicholsonia Schum.

42 - Borreria angustifolia Schl.

43 - Borreria argentea Cham.

44 - Borreria Bradei Standl.

45 - Borreria capitata (R. \& P.) DC.

46 - Borreria centhranthoides Schul.

47 - Borreria corymbosa (R. \& P.) DC.

48 - Borreria cupularis DC.

49 - Borreria eryngioides Cham. \& Schlechtd.

50 - Borreria hispida Spr.

51 - Borreria laevis Grizeb.

53 - Borreia latifolia Schum.

53 -Borreria laxa Cham. \& Schlechtd.

54 - Borreria nana Standl.

55 - Borreria poaya DC.

56 - Borreria poaya (St. Hil.) DC. var. stenophylla K. Schum.

57 - Borreria Runlsii K. Schum.

58 - Borreria scabeosoides Schl.

59 - Borreria suaveolens Mey.

60 - Borreria tenella Schl.

61 - Borreria thalictroides K. Schum.

62 - Barreria valerianoides Schl.

63 - Borreria verticillata (L) Mey.
64 - Bothryospora corymbosa Hook $f$.

65 - Botryarrhena pendula Ducke

66 - Bouvardia febrifuga Wedd.

67 - Bouvardia hirtella H. B. K.

68 - Bradea brasiliensis Standly

69 - Calycophyllum acreanum Ducke

70 - Calycophyllum obovatum Duc$\mathrm{ke}$

71 - Capirona decorticans Spruce

72 - Capirona Huberiana Ducke

73 - Capirona surinamensis Brem.

74 - Cephaelis apendiculata Schum

75 - Cephaelis barcelana Standl.

76 - Cephaelis biternata Standl.

77 - Cephaelis blepharophylla Stand1.

78 - Cephaelis Bradei Standl.

79 - Cephaelis colorata Wild.

80 - Cephaelis crebrinervis Standl.

81 - Cephaelis Duckei Standl.

82 - Cephaelis flaviflora Standl.

83 - Cephaelis glabra Willd.

84 - Cephaelis glabrescens Standl.

85 - Cephaelis hastisepala Standl.

86 - Cephaelis horridula Shum.

87 - Cephaelis humbolddtiana ornata Standl.

88 - Cephaelis iodotricha Standl.

89 -Cephaelis involucrans Muell. Arg.

90 - Cephaelis ipecacuanha A. Rich.

91 - Cephaelis Kappleri Standl.

92 - Cephaelis leucantha Standl.

93 -Cephaelis Muelleriana

94 - Cephaelis muscosa Sw.

95 - Cephaelis paraensis Standl.

96 - Cephaelis platypoda Standl.

97 -Cephaelis Poeppigiana Muell. Arg.

98 - Cephaelis rosea Benth.

99 -Cephaelis ruelliaefolia Cham. et Schlechdt.

100 - Cephaelis spathacea Standl.

101 - Cephaelis squarrosa Standl.

102 - Cephaelis subremota Muell.Arg.

103 - Cephaelis tomentosa Willd.

104 - Cephaelis tricoloba St. Hill.

105 -Cephaelis violacea Willd.

106 - Cephalanthus breviflorus Schum.

107 - Cephalanthus peruvianus Schum.

108 - Chimarrhis barbata (D.) Brem.

109 - Chimarrhis glabriflora Ducke

110 - Chimarrhis turbinata DC. 
111 - Chiococca alba Hitch.

112 - Chiococca brachyata R. et. Pav.

113 - Chytropsis guianensis Brem.

114 - Cinchona amazonica Standl.

115 - Cinchona Calysaia Wedd. var. Josephiana

116 - Cinchona carabayensis Wedd.

117 - Cinchona Ledgeriana Moens.

118 - Cinchona Mutisii Lamb.

119 - Cinchona officinalis L.

120 - Cinchona succirmhrn Par.

121 - Coccocypselum Bradei Standl.

122 - Coccocypselum condalia Pers.

123 - Coccocypselum cordatum Krause

124. - Coccocypselum erythrocephalum Sthl.

125 - Coccocypselum glabrifolium Standl.

126 -Coccocypselum guianensis Schum.

127 - Coccocypselum Krauseanum Standl.

128 - Coccocpselum lanceolatum et P.) Pers.

129 - Coccocypselum Lyman Smithii Standl.

130 -Coccocypselum pedunculatum Standl.

131 - Coccocypselum pumilio Standl.

132 - Coccocypselum sessiliflorum Standl.

133 - Congdonia coerula Muel Arg.

134 - Cosmibueng obtusifolia $\mathbf{R}$. et P.

135 - Coussarea bevensis Britton

136 -Coussarea capitata Benth. et. Hook

137 -Coussarea confertiflora Muell. Arg.

138 - Coussarea contracta (Walp.) M. Arg.

139 - Coussarea Duckei Standl.

140 - Coussarea foetida Muell. Arg.

141 - Coussarea gracilifolia Benth. et Hook

142 - Coussarea grandis Muell. Arg.

143 - Coussarea hyacintiflora Standl.

144 - Coussarea hydrangifolia B. H.

145 - Coussarea insignis Ducke

146 - Coussarea japurana Standl.

147 - Coussarea leptoloba Muell. Arg.

148 - Coussarea leptophragma Muel. Arg.

149 -Coussarea locuples Standl.
150 - Coussarea longifolia Muell. Arg.

151 - Cousscrea macrantha Standl.

152 - Coussares macrophylla Mart.

153 - Coussarea megistophylla Standl.

154- Coussarea paniculata Standl.

155 - Coussarea porophylla M. Arg.

156 - Coussrrea racemosa A. Rich.

157 - Couss:

158 - Coussarer violacea Aubl.

159 - Coutarea hexandra Schum.

160 - Coutarea hexandra Schum. var. amazorice.

161-Coutarea hexandra Schum. var. pubescens

162 - Declieuxir Bradei Standl.

163 - Declieuxia brasiliensis M. Arg.

164 - Declieuxia bouvardioides Standl.

165-Decliouxia cacuminis Muell. Arg.

166 - Declipuxir! calophylla Standl.

197 - Decli'nuxia censnthoides Muell. Arg. var. stenophulla

168 -Declieuxia chiococcoides H. B. $\mathrm{K}$.

169 - Decliquxia cordigera M. Zucc. var. genuino.

170 - Decliєuxia deltoides Muell. Arg.

171 - Decliєuxia diantheroides Standl.

172 - Decli uxiz divergentiflora DC.

173 -Decliruxia fruticosa Krause

174-Decli uxid intermedia Muell Arg.

175 - Decli uxia origanoides Zucc.

76 - Decliraxia polygaloides Zucc.

1?7-Decliruxia sntureoides Muell. Arg.

178 - Dend: osipanea spigelioides Ducke

179 - Depp sa umbellata Hemsl.

180 - Dirlyretrlanthus fuscescens Kuhl:n.

181 - Didy ?aea mexicana Hook f.

182 - Diodia alata Nees \& Mart.

183 - Diodir articulat. DC.

184 - Dicdi a Barbeyana Abul.

185 - Diod' $x$ brasiliensis Spreng.

185 - Diodiz dasycephala Cham. \& Schlechtd.

¿87 - Diodia gymnocephala Schum.

130-Diodia hypsopifolia

Cham. \& Schlechtd.

(Willd.)

i 89 - Diodia Kuntzii Schum. 
190 - Diodia ocimifolia Brem.

191 - Diodia paradoxa Schl.

192 - Diodia polymorpha Schl.

193 - Diodia prostrata Sw.

194 - Diodia saponarifolia Schl.

195 - Diodia Schumannii Standl.

196 - Diodia setigera DC.

197 - Diodia teres Walt.

198 - Duroia Duckei Hub.

199 - Duroia eriopila L. f.

200 - Duroia fusifera Hook 1.

201 - Duroia hirsuta Schum.

202 - Duroia longiflora Ducke

203 - Duroia macrophylla Hub.

204 - Duroia palustris Ducke

205 - Duroia paraensis Ducke

206 - Duroia peciolaris Hook $\mathrm{f}$.

207 - Duroia saccifera (Mart.) Hook $f$.

208 - Duroia Sprucei Rosb.

209 - Duroia triflora Ducke

210 - Duroia vellutina Hook $f$.

211 - Emmeorrhiza umbellata (Spreng.) K. Schum.

212 - Faranea amazonica Muell. Arg.

213 - Faramea anisocalyx Poepp.

214 - Faramea bracteata Muell. Arg.

215 - Faramea calyciflora A. Rich.

216 - Faramea capilipes Muell. Arg.

217 - Faramea congesta Hub.

218 - Faramea crassifolia Benth.

219 - Faramea diversifolia Muell. Arg.

220 - Faramea egensis Muell. Ar.

221 - Faramea fallax Muell. Arg.

222 - Faramea glandulosa Poepp. et E.

223 - Faramea hyacintha Mart.

224 - Faramea longifolia Benth.

225 - Faramea macroura Standl.

226 - Faramea Martiana Muell. Arg.

227 - Faramea maynensis Spruce

228 - Faramea miconioides Standl.

229 - Faramea montevidensis (Cham. \& Schlechtd.) DC.

230 - Faramea Nettoana Muell. Arg.

321 - Faramea occidentalis Muell. Arg.

232 - Faramea pachydictyon Muell. Arg.

233 - Faramea platyclada Muell. Arg.

234 - Faramea Poeppigii Muell. Arg.

235 - Faramea pulchella Spruce

233 - Faramea quinqueflora $\mathbf{P}$. et $\mathbf{E}$.

237 - Faramea salicifolia Presl.

238 - Faramea singularis Standl.
239 - Faramea stipulacea (Cham. \& Schlechtd.) DC.

240 -Faramea subbasilares Muell. Arg.

241 - Faramea tetragona M. Arg.

242 - Faramea torquata Muell. Arg.

2:3 - Ferdinandusa chlorantha Standl.

244 - Ferdinandusa cordata Ducke

245 - Ferdinandusa elliptica Pohl.

246 - Ferdinandusa guianensis Spruce

247 - Ferdinandusa hirsuta Standl.

248 - Ferdinandusa lanceolata Schum.

249 - Ferdinandusa nitida Ducke.

250 - Ferdinandusa paraensis Ducke

251 - Ferdinandusa rudgeoides Hook $f$.

252 - Ferdinandusa Sprucei Schum.

253 - Galium Andrewsii Gray

254- Galium aparine L.

255 - Gardenia jasminoides Ellis

256 - Genipa caruto H. B. K.

257 - Geophyla cordata Muell. Arg.

258 - Geophyla herbacea O. Ktze.

259 - Gleosonia macrocalyx Ducke

260 - Gleosonia uaupensis Ducke

261 - Gonzalagunia cornifolia

262 - Gonzalagunia hirsuta Schum.

263 - Gonzalagunia spicata (Lam.) Gomez

264 - Guettarda aff. viburnoides

Cham. Schl.

265 - Guettarda angelica Mart.

266 - Guettarda argentea Lam.

267 - Guettarda aromatica Poepp. et Endl.

268 - Guettarda grandiflora Steid.

269 - Guettarda sericea Muell. Arg.

270 - Guettarda Uruguensis Cham. \& Schlechtd.

271 - Guettarda viburnoides Cham. \& Schlechtd. var. pannosa M. Arg.

272 - Hamelia patens Jacq.

273 - Hemidioidia oxymifolia Schum.

274 - Henriquezia macrophylla Ducke

275 - Henriquezia verticillata Spruce

276 - Hillia illustris (Vell.) Schum.

277 - Hillia parasitica Schum

278 - Hillia viridiflora Kuhl.

279 - Hindsia breviflora Schum.

280 - Hindsia longiflora Benth.

281 - Hippotis tubiflora Schum.

282 - Hoffmannia Dusei Standl.

283 - Isertia bulata Schum.

284 - Isertia coccinea Vahl. 
285 - Isertia glabra Ducke: :

286 - Isertia hypoleuca Benth:

287 - Isertia longifolia Schum.

288 - Isertia parviflora Vahl:

289 - Isertia rosea Spruce

290 - Isertia spiciformis DC

291 - Isertia Weberbauerei StandI.

292- Isidorea amoena A: Rich.

293 - Ixora densiflora Muell. Arg.

294i Ixora Duckeii Standl.

295 - Ixora Gardneriana Benth.

296 - Ixora pubesoens Willd.

297 - Ixora syringaeflora. (Schlechtd.) Muell. Arg.:

298 - Ixora tmuncata Murell. Arg.

299 - Ixorai venulosa. Benth :

300 - Kotchubraea insignis Fisch.

301 - Kotchubaea palustris Ducke

- 302 - Kotchubaea, semisericea" Ducke

303 - Kotchubaea sericanta Standl.

304 - Ladenbergia amazonense Ducke

305 - Ladenbergia hexandra: K1. :

301 - Ladenbergia Lambertiana Klotz.

307 - Ladenbergia magnifolia (Rot.) $\mathrm{KL}$.

308 - Ladenbergia paraensis Ducke

309 - Ladenbergia pedunculata Schum.

310 - Lipostoma capitata Aubl.

311 - Machaonia brasiliensis" Schl. ..

312 - Machaonia Spinosa Schl.

313 - Macrocriemum roseum Wedt.

314 - Malenea bahiensis Muell. Arg.

315 - Malanea boliviana Standl.

- 316 - Malanea brasiliensis Muell. Arg.

317 - Malaenai Duekei Standl.

318 -Malanea gabrielensis Muell. Arg.

319 - Malanea macrophylla-Bartl.

320 - Malanea ribesioides Schum.

321 - Malanea sarmentosa Aubl.

322 - Manettia Beyrinchiana Schum.

323 - Manettia congesta Sch.

$324-$ Manettia divaricata. Wernh.

325-Manettia fimbriata Schum.

328 - Manettia Glaziovii Wernh.

327--Manettia gracilis Cham.-et Schl.

328 - Manettia ispida . Poepp.

329 - Manettia Hoehnei Standl.

330. - Manettia, ignita Shum. 'var.cordifalia

331 - Manettia luteo-rubra Benth.

332 -Manettia mitis Schum.

333 - Manettia parilina Standl.
334 - Mapieitia pedunculata Schum.

335 - Mapettia pubesoens Cham.

336 -Menettia :verticilata Wernham.

337 - Mapouria alba Muell. Arg.

338 - Mapouxia-brevicallis Muell. Airg.

339 - Mapouria cearensis Hub.

340 - Mapouria chionantha DC.

341 - Ma ouria Focheana (Miq.) Brem.

342 - Mapouria formosa Muell. Arg.

343 - Mapouria Martianx-Muell. Arg.

344-Mapouria podacephala ' Muell.

Art.

345 - Mapouria vasivensis Muell. Arg.

346 - Melanopsidium nigrum: Cels:

347 -Mitracarpus frigidus (Willd.)

K. Schum.

348.- Mitracarpus hintus (L). DC.

349 - Mitracarpus hirtus (L) DC. forma

350 - Mitracarpus, microspermus Schum.

351 - Mitracarpus selloanus. Schum.

352 - Molopanthera paniculata. Turcz.

353 - Mussaenda aff. luteola DC.

354 - Nepbertia gracilis Wernh.

355 - Nothopleura tapajosensis Bṛem.

356 - Otdenlandia corymbosa, $L$.

357 - Oldenlandia herbacea Roxb.

358 - Oldenlandia macrophylla DC.

359 - Olqenlandia tenuis Schum.

3E0 - Oldenlandia tesifolia Schum.

361 - Pagamea caudata Hub.

362 - Pagamea coriacea Spruce …

363 - Pagamea guianensis Aubl. $\because$

364 - Pagamea hirsuta Spruce

365 - Pagamea macrophylla Spr. et Benth.

366 - Pagamea plicata Spruce

367 - Pagamea thyrsifolia Benth.

368 - Palicourea bracteosa Standl.

369 - Palicourea charianthema Standl.

370 -Palicourea comitis (Muell.) Standl.

371 - Palicourea corymbifera (Muell.)

Stendl.

372 - Palicourea crocea $R$. et $L$.

373 - Palicouriea cuyabensis Schul.

374 - Palicourea decipiens Muell. Arg

375 - Palicourea elegans Poepp.

376 - Palicourea fastigiata .H.B.K.

377--Palicourea fraterna (Muell.) Standl.

378 - Palicourea guianensis Hub.

379 - Palicourea juruana Krause 
380 - Palicourea Lagesi Krause

381 - Palicourea leuconeura Standl.

382 - Palicourea longepedunculata Garda.

383 - Palicourea longepedunculata Gardn. var. pubescens

384 - Paliçgurea Marcoravii St. Hil..

385 - Palicourea Mello-Barretoi Standl.

3\&5 - Palicourea nicotiniaefolia Schul.

387 - Palicourea nigricans Krause

388 - Palicourea obscurata (Muell.) Standl.

389 - Palicourea officinalis Standl. var.' rigida

\$90 - Palicourea ovata Kuhl.

991 - Palicourea paraensis (Muell.) Stsndl.

392 - Palicourea platypodina Standl.

393 - Palicourea radians (M. Arg.) Stəndl.

394 - Palicourea resiflora Krause

395 - Palicourea. squarrosa Standl.

396 - Paliçourea subspicata Hub.

397 - Palicourea subulata Hub.

398 - Palicourea triphylla DC.

399 - Palicourea virens Standl.

400 - Paliçourea Wedeliana (Muell.) Standl.

401 - Palicourea zanthocephala Muell. Arg.

102 - Paederia olens Schum.

403 - Parachimarrhis breviloba Ducke

404 - Pentagonia atricapilla Brem.

405-Pentagonia gigantifolia Ducke

406 - Pentagonia spathicalyx Schum.

407 - Peráma dichotoma Poepp.

08 - Perama galioides Poir.

409 - Perama hirsuta Aubl.

410 - Perama sparsiflora Standl.

A11 - Platycarpum negrense Ducke

412 - Pletycarpum orenocense H.B.K

413 - Pogonopus tubulosus Schum.

414 - Posoqueria acutifolia Mart.

415 - Posoqueria brachyantha Standl.

416 - Posogueria latiflora R. at Schum.

417 - Posoq́ueria longiflora Aubl.

418 - Psyckotria carthagenensis Jacq.

419 - Psychotria coriacea Schum.

420 - Psychotria estrelana Muell. Arg.

421 - Psychotria forsteronioldes M. ArF:
422 - Psychotria Gardneriana Muell. Arg.

423 - Psychotria hancorniaefolia Benth.

424 - Psychotria hasticephala Muell. Arg.

425 - Psychotria hervinha Glaz.

426 - Psychotria janeirensis Muell. Arg.

\$27-Psychotria malaneoides Muell. Are.

428 - Psychotria nemorosa Glaz.

429 - Prychotria pilosa Glsz.

\$50 - Psychotria rubra Muell. Arg.

in1 - Fsychotiria sessiliflora Glaz.

432 - Psychotria sessilis Vell.

433 - Psychotria subtriflora M. Arg.

434 - Psychotria suterella M. Arg.

435 - Pschotria tabacifolia Muell. Arg.

436 - Psychotria Velloziana Benth.

437 -.Psychotria velutipes Muell. Arg.

438 - Psyllocarpus asparagoides Mart.

439 - Psyllocarpus laricoides Mart. \& Zucc.

440 - Rindia armata DC. var. pubescens.

441 - Randia densiflora Bartl.

442 - Randis formosa (Jacq.) Schum.

443 - Rendia Ruiziana DC.

444-Relbunium buxifolium Schum.

445 - Relbunium hipocarpium (L) Hensl.

446 - Relbunium hirtum Schum.

447 - Relbunium ovale Schum.

448 - Remijia amazonica -Schum.

449 - Remijia asperilla Stándl.

450 - Remijia Duckei Standl.

451 - Remijia ferruginea DC.

452 - Remijia glomerata Hub.

453 - Remijia ' hispidn Schü.

454 - Remijia "tenififlora Benth.

455 - Remijia Ulei Krause

356 - Retiniphyjlum ndiaritum Standl.

457-Retiniphylum cotaractae Ducke

458 - Retiniphylum chloranthum Ducke :?

459 - Retiniphylum concolor M. Arg.

460 - Retinipkylum Kuhlmanii Standl. :

461 - Retiniphylum pilosum Benth.

462 - Retiniphylum Schomburgkii M. Arg.

463-Retiniphylum truncatum M. Arg. 
464 - Richardia acutifolia (Krause) 511 - Sickingia Oliveri Schum. Standl.

512 - Sickingia pisoniformis Schum.

465 - Richardia astroites (K. Schum.) 513 - Sickingia Sampaioana Standl. O. Ktze.

514 - Sickingia tinctoana (H. B. K.) Schum.

466 - Richardia brasiliensis Gomez

467-Richardsonia rosea St. Hil.

468 - Richardsonia scabra St. Hil.

515 - Sickingia xanthostema Schum.

516 - Sipanea biflora L. 1.

469 - Richardsonia stellaris Cham. 517 - Sipanea glomerata H. B. K. Schl.

518 - Sipanea pratensis Aubl.

470 - Rondelettia ligustroides Hemsl. 519 - Sommera lanceolata Krause

471 - Rondelettia rupicola Schum.

520 - Sommera sabicioides Schum.

472 - Rubia tinctoria Salisb.

473 - Rudgea Blanchetiana M. Arg.

474-Rudgea coriacea Schum:

475 - Rudgea corniculata Benth.

47.6 - Rudgea Dahlgrenil Standl.

477 - Rudgea Duckei Standl.

478. Rudgea eriantha Benth.

479 - Rudgea fimbriata . Standl.

521 - Spermacoce verbenoides Lk.

522 - Spermacoce verticillata L.

523 - Sphinctanthus acutilobus Hub.

524 - Sphinctanthus ruprestis Benth.

525 - Stachyarrhena, acuminata : Standl.

526 - Stachyarrhena brevispicata Standl.

480 - Rudgea Franoavilleana M. Arg. 527 - Stachyarrhena Duckei Standl.

481 - Rudgea Gardenioides M. Arg. 528 - Stachyarrhena longifolia Hook 1.

482 - Rudgea gracilifolia Standl.

483 - Rudgea inurbana Standl.

484 - Rudgea ipanensis M. Arg.

485 - Rudgea jacobinnensis M. Arg.

486 - Rudgea jasminoides M. Arg.

487 - Rudgea lanceolata Benth.

488 - Rudgeq longipes Standl .

489 - Rudgea macrophylla Benth.

529 - Stachyarrhena spicata Hook 1.

530 - Staelia aurea Schum.

531 - Staelia catechosperma K. Schum.

532 - Staelia reflexa DC. e St. vestita R. Schum.

533 - Standleya erecta Brade

534 - Standleya Limae Brade

490 - Rudgea major (Cham.) M.Arg.

491 - Rudgea Martiana M. Arg.

535 - Standleya prostrata (Schum.) Brade

492 - Rudgea meridionalis M. Arg.

536 - Striolaria amazonica Ducke

493 - Rudgea micrantha M. Arg.

494 - Rudgea nodosa Benth.

537-Thieleodoxa sorbilis (Hub.) Ducke

495 - Rudgeq ovalifolia Salisb.

496 - Rudgea pallida Schum.

497 - Rudgea paniculata Benth.

498 - Rudgea pleurocalyx Standl.

499-Rudgea subsessilis Benth.

500 - Rustia formosa Kl.

501 - Rustia gracilis Schum.

502 - Sabicea aspera Schul.

- 503-Sablcea paraensis (Schum.) Wernh.

538 - Thieleodoxa stipularis Ducke

539 - Thieleodoxa verticillata Ducks

540 - Tocoyena brasiliensis Mart.

541 - Tocoyena bullata (Vell.) Mart.

542 - Tocoyena foetida Poepr. et Standl.

543 - Tocoyena formosa Schum.

544 - Tocoyena guianensis Schum.

545 - Tocoyena longiflora Aubl.

546 - Tocoyema Sellowiana Schum.

504 - Sabicea umbellata Pers.

547 - Tocoyena Wilhamsii Standl.

548 - Ucriana longifolia Spreng.

505 - Sabicea vilosa R. et S.

509 -Sarcocephalus esculentus Afzel.

507 - Schreibersia lanceolata Pohl.

508 - Schradera brasiliensts Mart.

549 - Uncaria guianensis Gmel.

550 - Warszewiczia coccinea . Fl.

551 - Warszewiczia elata Ducke

509 - Sickingla Glaziovti Schum

552 - Warszewiczia Sctivackei Schum

510 - Sickingia japurendis Schum.

553 - Warszevoiczia splendens W'edd. 


\section{RESUMO E CONCLUSOES}

As minhas primeiras observações sóbre a ocorrência das céfulas anexas dos estomatos na familia Rubiaceae faram feltas na eplderme foliar de Coffea arabica L.. Em seguida; examinel a epiderme de 20 espécies, pertencentes a 9 gèneros c cultivadas no Parque da E. S. A. "Luiz de Queiroz". Em virtude da constância das células anexas, analisei, a princípio, aś espécies e variedades de Coffea (ao todo 28 individuos) existentes na coleçáo de cafés do Instituto Agronómico de Campinas e, depois, o maior numero de gêneros e espécies da familia. Para a realização desse trabalho, solicitei de várias instituiçōes matelial botánico, tanto vivo como herborizado, constante de 10lhas; consegui reunir, assim, copiosa quantidade de espécles. Feita a separação das duplicatas e das folhas de epiderme de difícil extraçåo, as espécies se reduziram a 553.

Do exposto neste e nos trabalhos que publiquel $(1,2)$, posso concluir que as duas células anexas dos estómatos, na familla Rublaceae, constituem um caráter anatómico de familia, multo embora me faltem alguns generos para seu estudo completo. Minha conclusåo se apoia nos tres pontos básicos seguintes :

1 - Que as duas células anexas dos estómatos, com as caracteristicas descritas, ocorrem entre as Rubiales somente na familia Rubiaceae.

2 - Que as espécies estudadas' até agora revelaram, sem exceção, as duas células anexas nos estómatos.

- 3 - Que as células anexas poderăo constituir, no caso de sua inconstância, um caráter diferencial de espécie ou de genero.

1

\section{VII - ABSTRACT}

In the present paper the author gives the final results of his studies about the significance of the two annex cells of the stomata of the Rubiaceae as anatomical family character, part of which has been previously published.

After having verified that in the Order Rubiales the Family Rubiaceae is the unique to show stomata provided with two annek cells differing in size and shape, the author has extended his observation over 553 species belonging to 107 genera, having not found till the present time a single discrepant case. Even though in the future some species not yet investigated come to show stomata devold of annex cells, even in this 
case the annex cells do not lose their importance at least as specific or generic character. However, the author is inclined to consider, on the light of the facts in hand, the two annex cells of the Rubiaceae stomata as good anatomical family chalizcter.

\section{BIBLIOGRAFIA CONSULTADA}

1 - ACCORSI, W. R. - 1941 - Revista "O Solo", ano XXXIII, n. ${ }^{\circ}$ único, pgs. 27-37. Tip. Aloisi. Piracicaba.

2 - ACCORSI, W. R. - 1944 - Anais da E. S. A. "Luiz de Queiroz", vol I, pgs. 157-175.

3 - LoefGreN, A. - 1917 - Manual das Famillas Phanerogamas, pgs. 500-514. Imprensa Nacional. Rio de Janeiro.

4 - KUHLMANN, J. G. - 1925 - Archivos do Jardim Botanico do Rio de Janeiro, vol. IV, p. 363-364. Ministério da Agricultuha. Rio de Janeiro.

5 - WetTsteIN, R. W. - Tratạo de Botanica Sistemática, p. 873. Editorial Labor, S. A. Argentina.

\section{IX - AGRADECIMENTO}

O Antor apresenta seus sinceros agradecimentos ao Dr. João Geraldo Kuhlmann, M. D. Diretor do Jardim Botanico do Rio de Janeiro, pela remessa de notável quantidade de espécies de Sinchona; a Dra. Odete Z. de Toledo, pelo trabalho de extracão das epidermes e ao Sr. Alvaro P. Sega pela feltura dos deserhos. 
ERRATA

A página 423, onde está : espécies de Cinchona;

Lêla-se : espécies de Rublaceae. Ao Dr. José E. T. Mendes, pelo envio de algumas espécles de Cinchona. 


\section{$\mathrm{X}$ - LEGENDAS}

Em tôdas as figuras, A e B representam as células anexas.

1 - Alibertia concolor (Cham.) K Schum.

2 - Alibertia myreifolia $\mathrm{K}$. Schum.

3 - Coussarea contracta (Walp.) M. Arg.

4 - Borreria poaya (St. Hil.) DC. var. stenophylla K. Schum.

5 - Coccocypselum lanceolatum (R. et P.) Pers.

6 - Relbunium hipocarpium (L) Hensl.

7 - Diodia hypsopifolia (Willd.) Cham. \& Schlechtd.

8 - Borreria verticillata (L) Mey.

9 - Galium aparine $\mathrm{L}$.

10 - Henriquezia verticillata Spruce

11 - Cephaelis ruelliaefolia Cham. et Schlechtd.

12 - Amajoua guianensis Aubl.

13 - Hamelia patens Jacq.

14 - Dialypetalanthus fuscescens Kuhlm.

15 - Palicourea radians (M. Arg.) Standl.

16 - Cosmibuena obtusifolia $R$. et $P$.

17 - Psyllocarpus laricoides Mart. \& Zucc.

18 - Rudgea Blanchetiana M. Arg.

19 - Psychotria suterella M. Arg.

30 - Cinchona Calysaia Wedd. var. Josephiana

21 - Chimmarrhis barbata (D.) Brem.

22 - Rubia tinctoria Sálisb.

23 - Bathysa australis (St. Hil.) Hook.

24 - Cinchona Ledgeriana Moens. 
Celui s anexas dos estốmatos na familia Rubiaceae
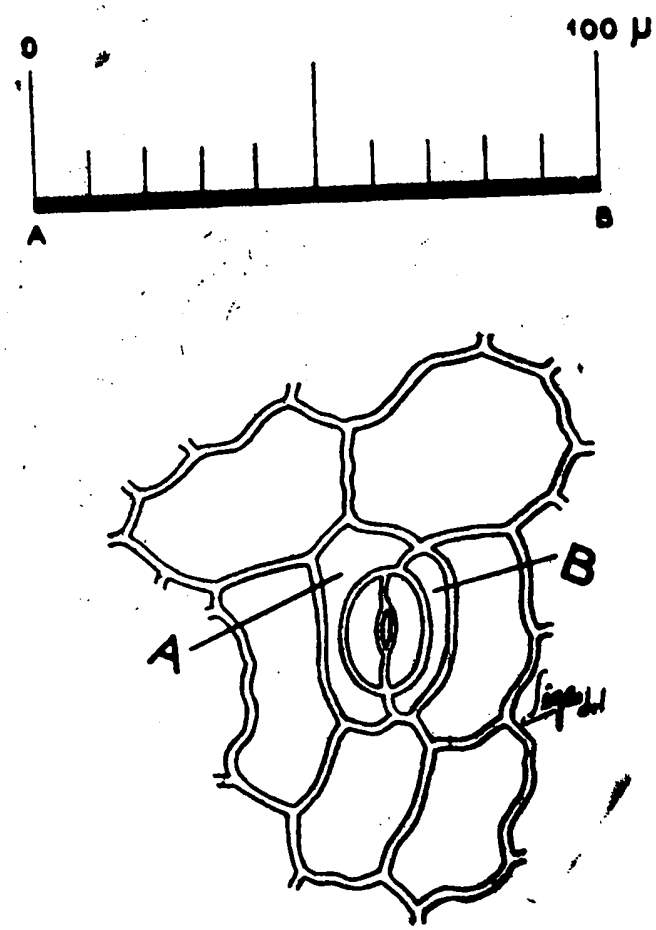

Fig. 1

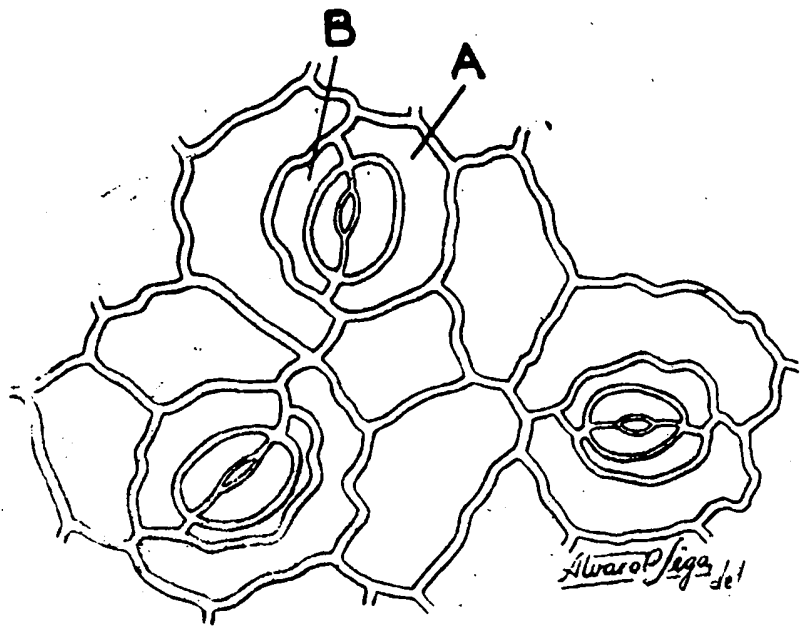

Fig. 2 


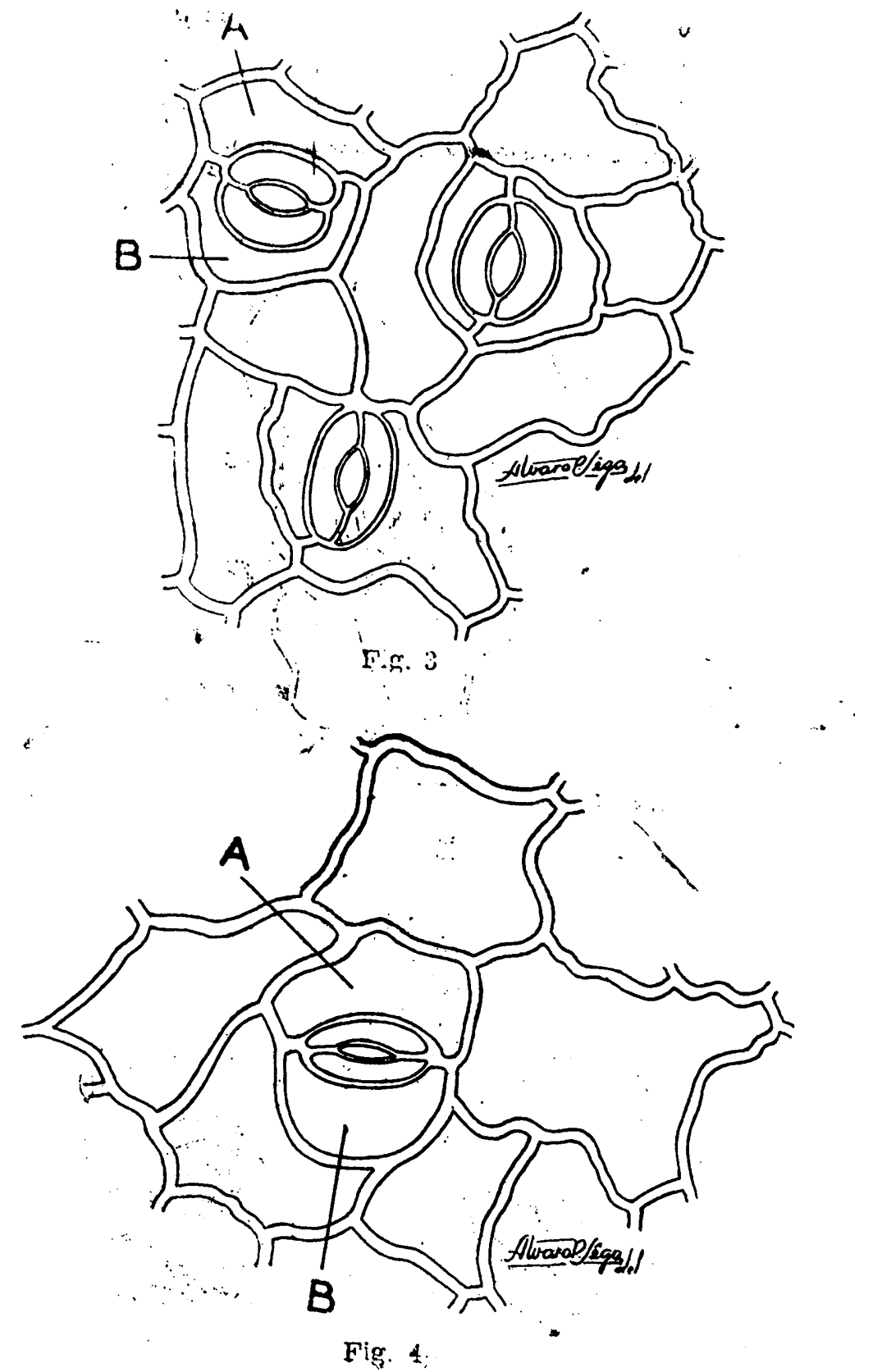



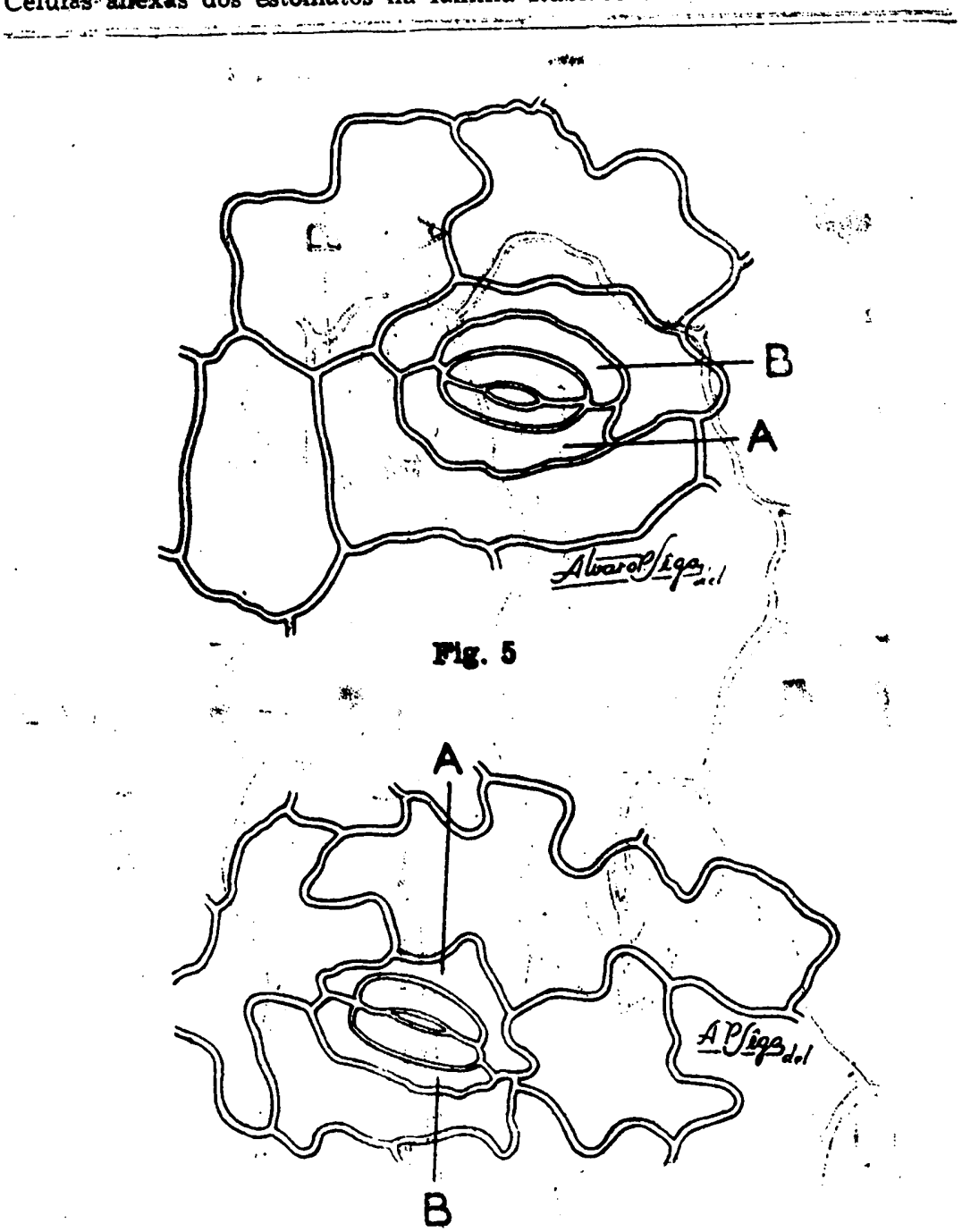

Fig. 6

W.

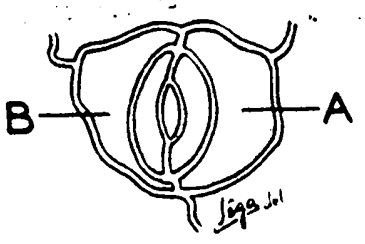

FHg. 7 
is

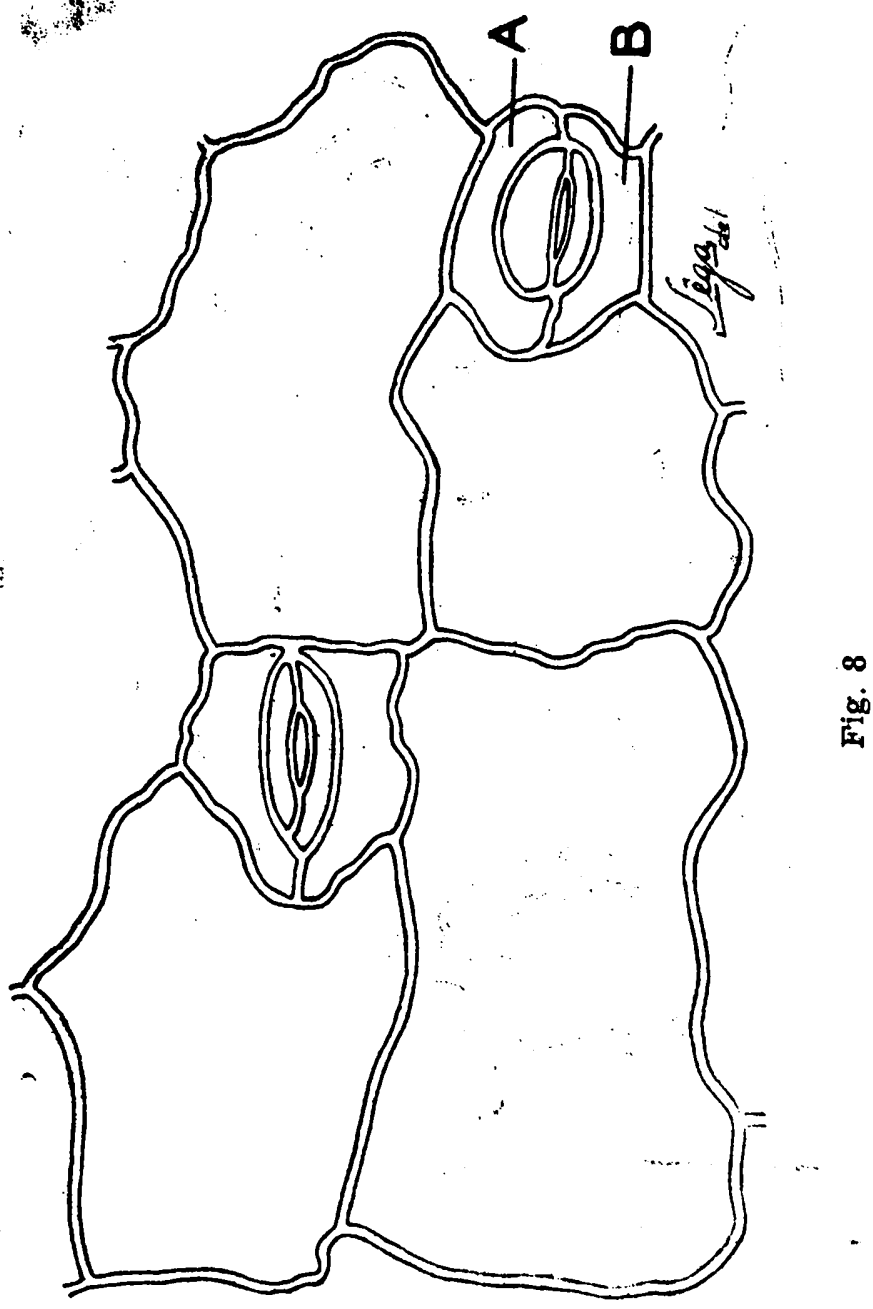



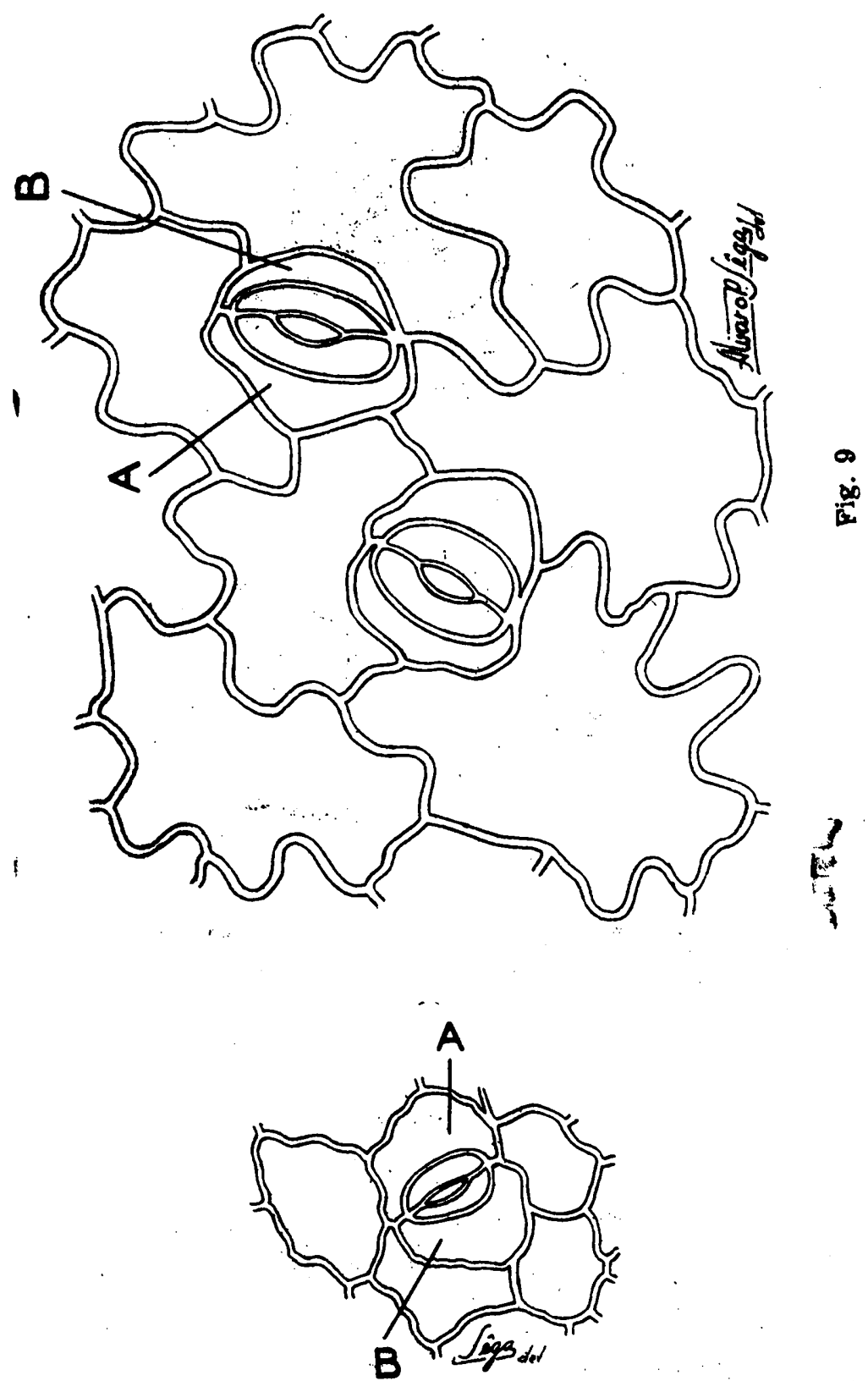

Fig. 10 


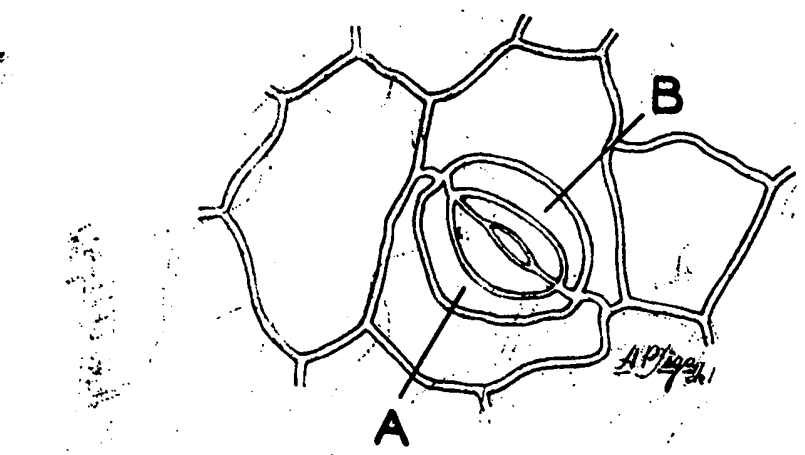

Figr. 11

$\because$

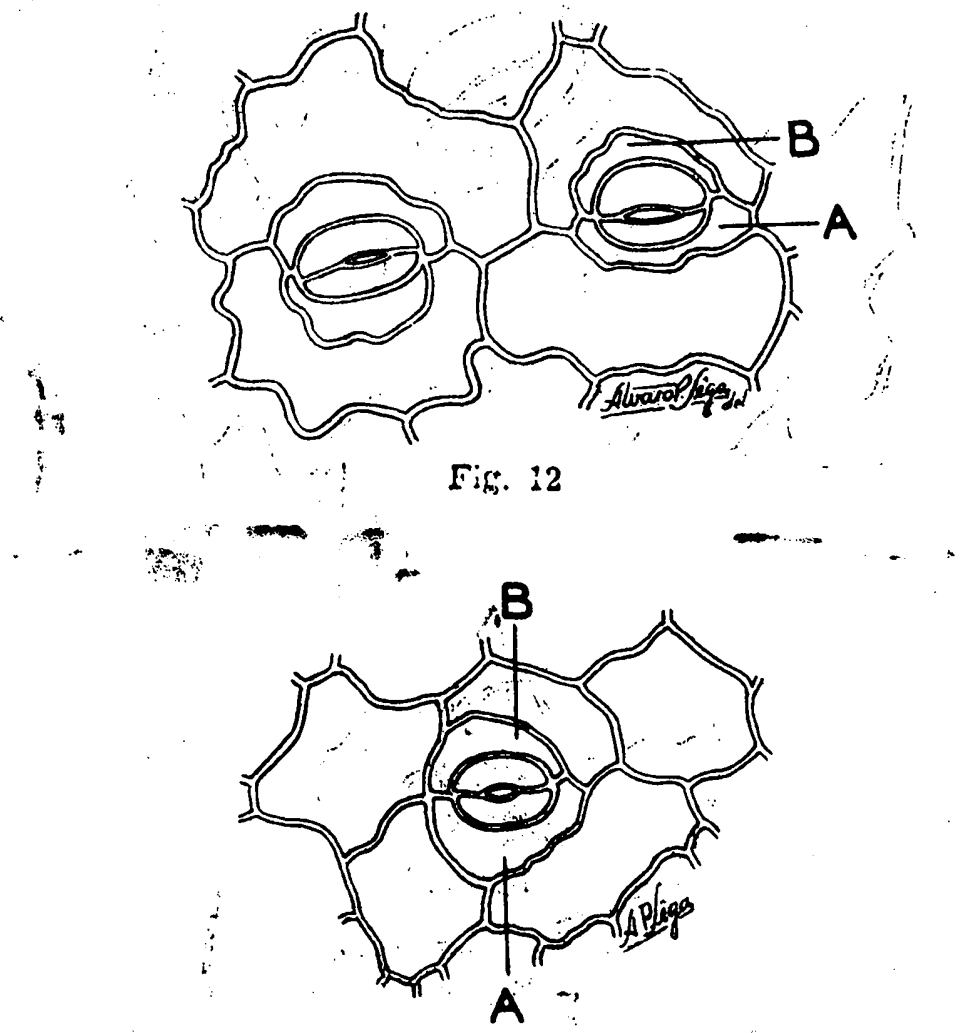

Fig. 13 


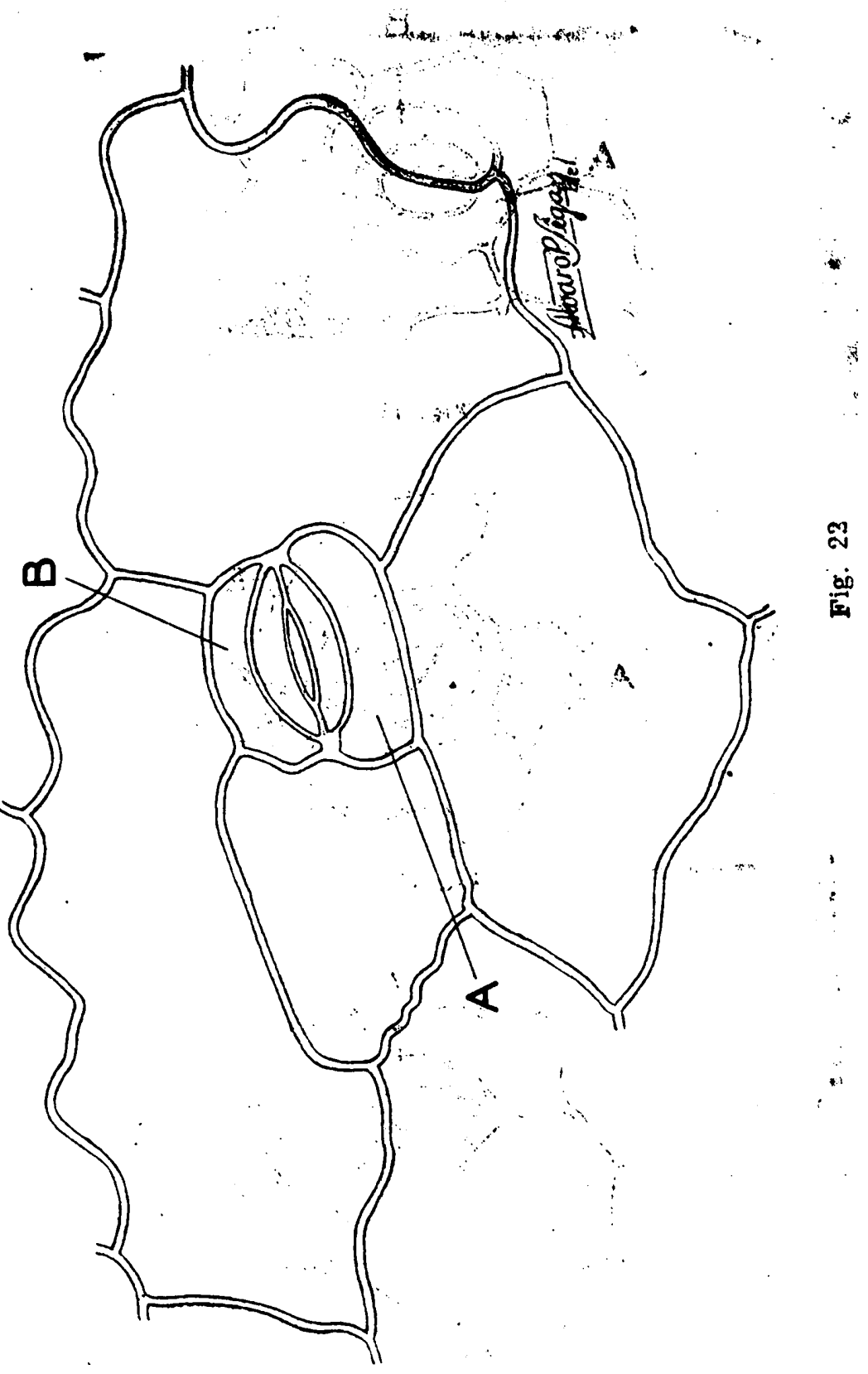




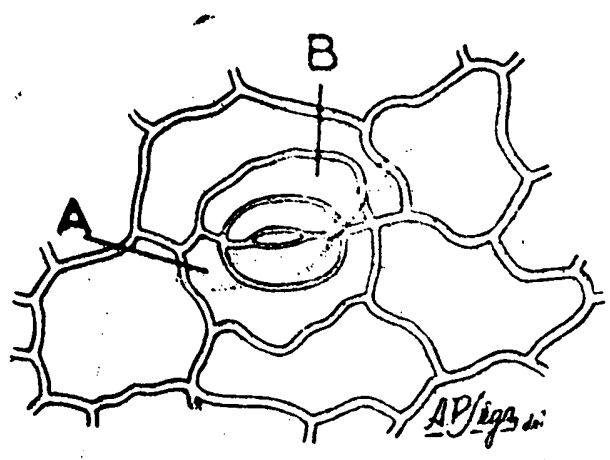

Fig. 15

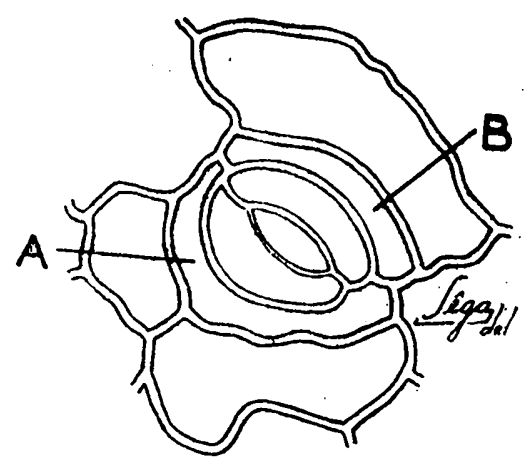

IIg. 16

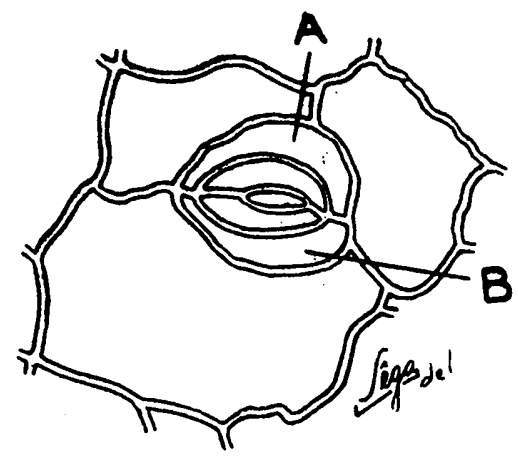

Fig. 17 


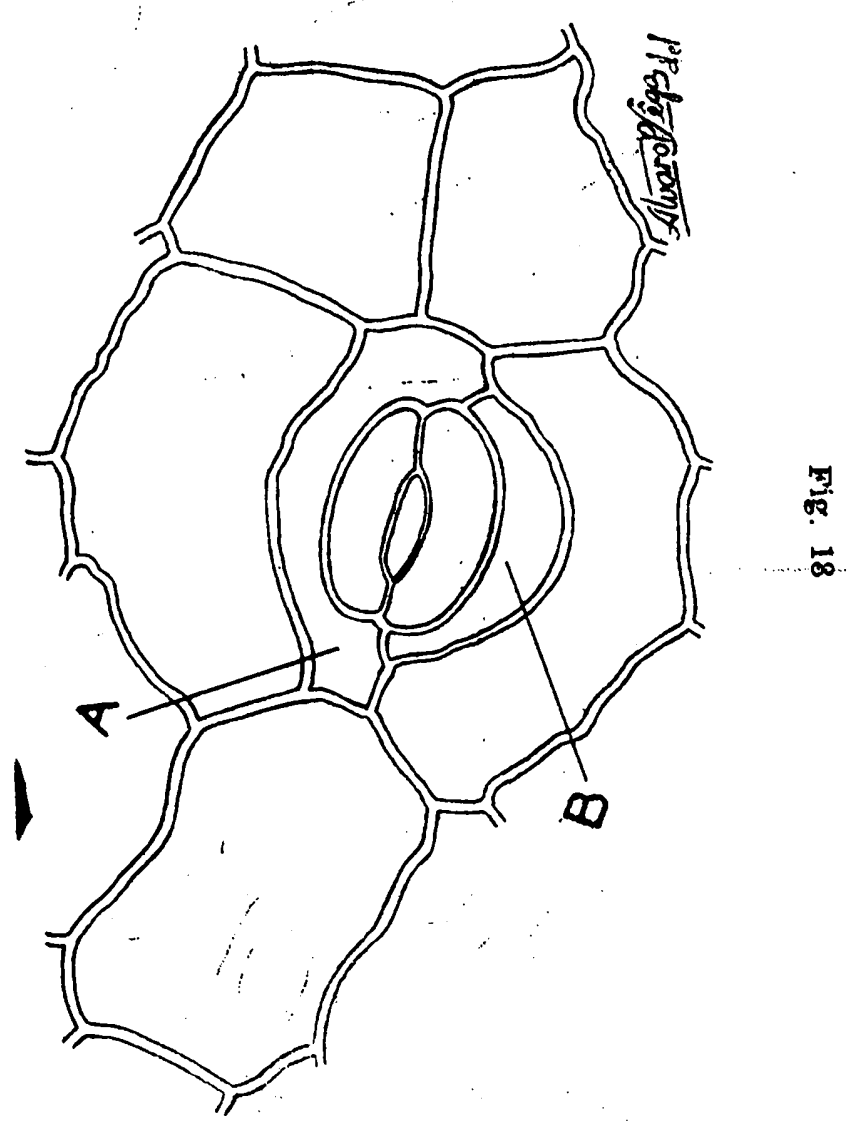


48

Anais da E. S. A: "Luiz de Queirez"
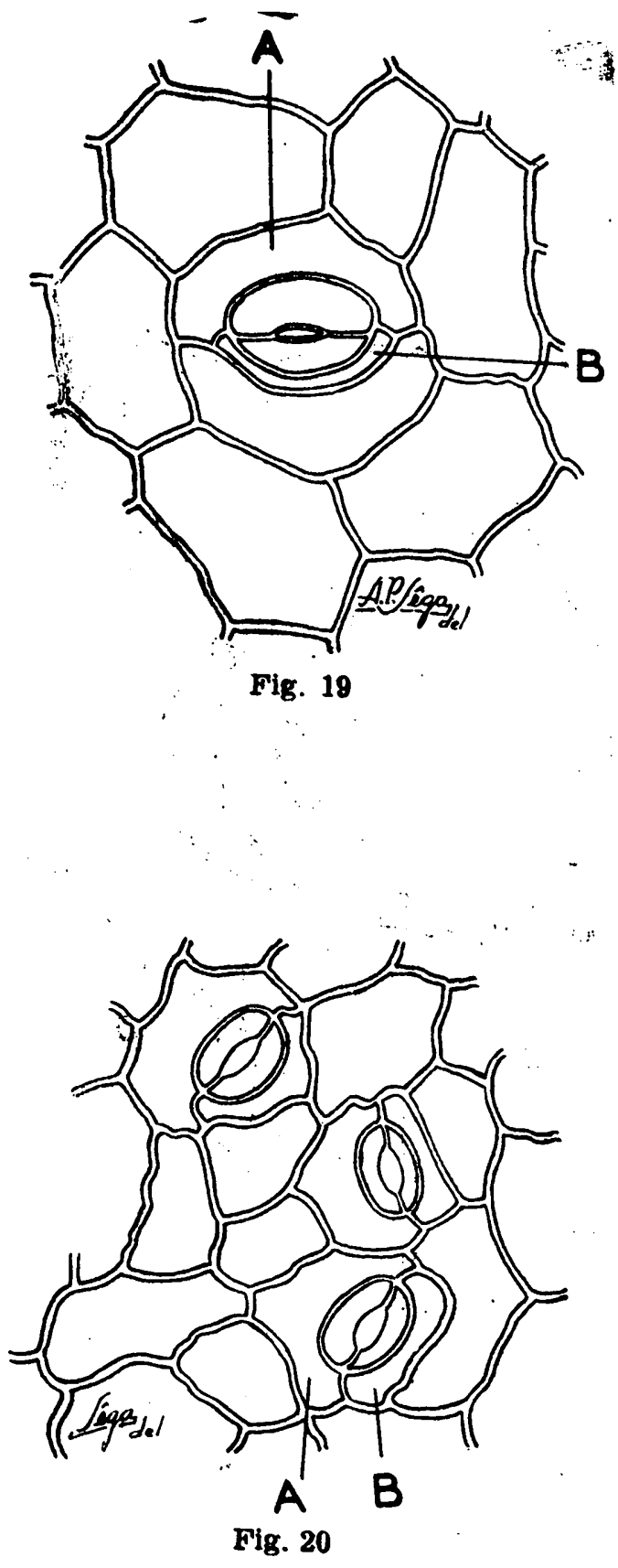
$\therefore$ and

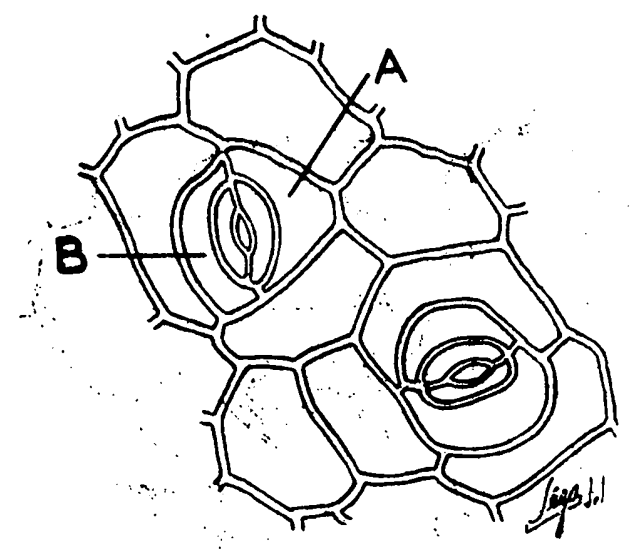

Fig. 21

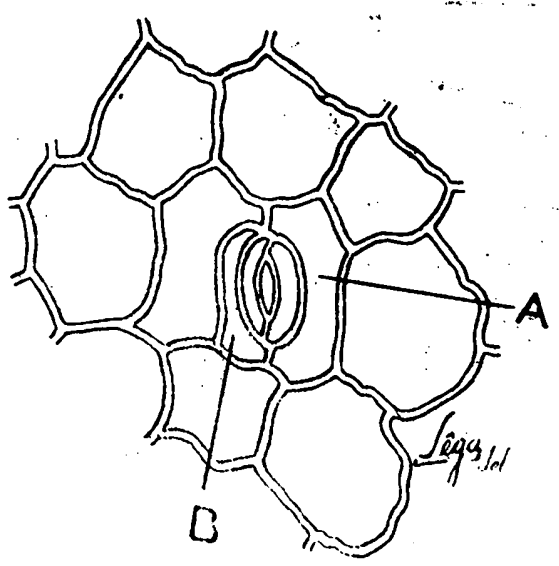

맏.5. 14 


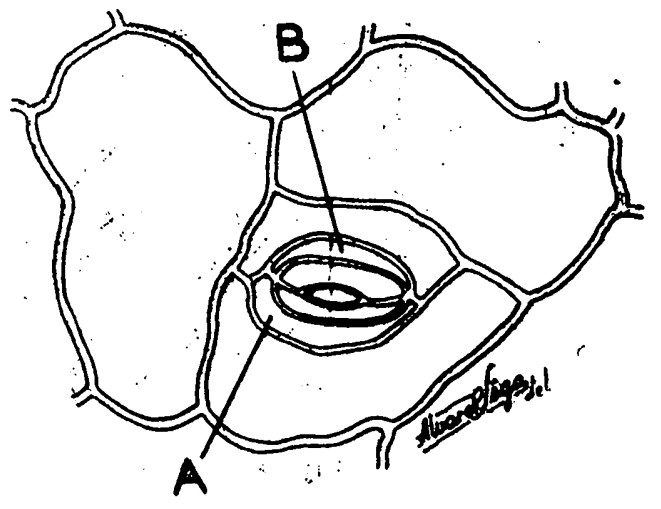

F:g. 23

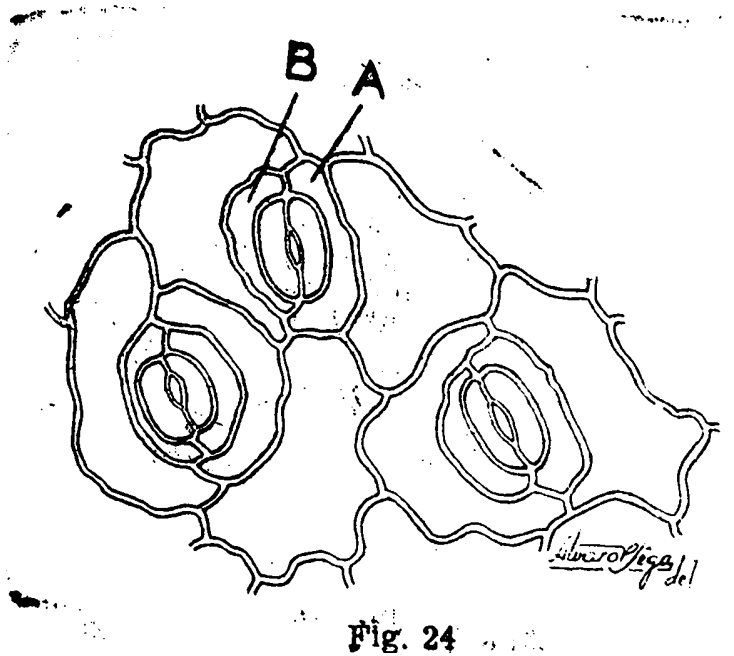

